\title{
OTIMIZAÇÃO DO NÚMERO DE PRIMERS EMPREGADOS EM RAPD PARA DETECTAR VARIABILIDADE GENÉTICA ENTRE ACESSOS DE PICÃO-PRETO
}

\author{
PRIMER NUMBERS OTIMIZATION FOR RAPD TO DETECT GENETIC \\ VARIABILITY AMONG HAIRY BEGGARTICKS ACCESS
}

Ribas Antonio VIDAL ${ }^{1}$

Fabiane Pinto LAMEGO²

Anderson Luis NUNES ${ }^{3}$

\begin{abstract}
RESUMO
Marcadores moleculares do tipo RAPD (polimorfismo de DNA amplificado ao acaso) estão entre os mais utilizados devido a sua facilidade de uso, rapidez e baixo custo. Através deste tipo de marcador é possível avaliar a estrutura e diversidade genética em populações naturais (plantas daninhas) e melhoradas. O objetivo deste trabalho foi avaliar a viabilidade da redução no número de primers utilizados em marcador molecular RAPD para conhecimento da variabilidade genética em populações de plantas daninhas. $O$ banco de dados de dois trabalhos diferentes com acessos de picão-preto (Bidens pilosa L.), conduzidos na Universidade Federal do Rio Grande do Sul (UFRGS), Porto Alegre, RS, foram avaliados quanto ao número de primers e efeito na variabilidade genética. Foi possível otimizar o número de primers utilizados por marcador RAPD. Quando poucos primers promovem boa formação de bandas em cada população, maior número de primers serão necessários para adequada estimativa da variabilidade genética.
\end{abstract}

Palavras-chave: Variabilidade genética, picão-preto, primers, marcador molecular.

\begin{abstract}
Molecular markers such as RAPD (Random Amplified Polymorphic DNA) are among the most widely used because they are easy to apply, quick and with low cost. With this marker it is possible to evaluate the structure and the genetic diversity in weed and crop populations. The objective of this work was to evaluate the viability of primer number otimization of RAPD molecular marker to know the genetic similarity of target populations. The data bank of two different experiments conducted with hairy beggarticks (Bidens pilosa L.) acesses, at Federal University of Rio Grande do Sul (UFRGS), Porto Alegre, RS, were evaluated on the effects of the primer numbers on the genetic variability. It was possible to otimize the primer number used by RAPD marker. When few primers promoted good band formation in each population, large number of prime will be necessary for the adequate estimative of genetic variability.
\end{abstract}

Key-words: Genetic variability, hairy beggarticks, primers, molecular marker.

\footnotetext{
${ }^{1}$ Eng. Agr. PhD., Professor Adjunto do Depto. de Plantas de Lavoura da Faculdade de Agronomia, UFRGS, Caixa Postal 15100, CEP: $91501-970$, Porto Alegre (ribas.vidal@ufrgs.br);

${ }^{2} E_{n g}{ }^{\underline{a}}$ Agr ${ }^{\underline{a}}$, MSC., Doutoranda do Programa de Pós-Graduação em Fitotecnia da UFRGS;

${ }^{3}$ Eng. Agr., Mestrado do Programa de Pós-Graduação em Fitotecnia da UFRGS.
} 


\section{INTRODUÇÃO}

A diversidade genética em populações de plantas pode ser determinada através de características morfológicas e agronômicas, isoenzimas e análises de marcadores moleculares como do tipo RAPD (polimorfismo de DNA amplificado ao acaso), entre outros $(6 ; 17)$. Por exemplo, em Sesamun indicum L., utilizou-se a técnica de RAPD para avaliar a variabilidade entre populações coletadas em quatro regiões da Turquia (1). Também em Setaria itálica (L.) P. Beauv. foi possível avaliar a diversidade genética entre trinta e sete acessos com a mesma técnica (13). Para Bidens pilosa L. (picão-preto), foi estimada a similaridade genética entre acessos resistentes aos herbicidas inibidores da enzima acetolactato sintase (ALS) por RAPD (3).

Marcadores moleculares permitem acessar a variabilidade genética ao nível de DNA das plantas. Existem diferentes técnicas que permitem identificar diretamente o polimorfismo de DNA e, portanto, marcar seqüências ou partes específicas do mesmo. Com marcadores moleculares é possível ter para cada gene de grande efeito um ou mais marcadores que podem ser utilizados para a identificação do fenótipo desejado (7). Marcadores como RAPD, Microssatélite e AFLP (polimorfismo de comprimento de fragmentos amplificados) são alguns dos mais utilizados em estudos genéticos (2).

A técnica de RAPD distingue-se das demais pelo fato de utilizar primers com 10 pares de bases de extensão, cuja seqüência nucleotídica é arbitrária, ao contrário das outras que requerem informações a respeito da seqüência do DNA alvo para o desenho de primers específicos (16). Dentre as diversas técnicas utilizadas, RAPD é a de menor custo, número de etapas e tempo para obter os resultados, além de fácil execução. Contudo, apresenta a desvantagem de ser de baixa repetibilidade e pouca consistência de um laboratório para o outro, o que dificulta a comparação de dados obtidos em diferentes locais (7).

Em geral, como não é necessário conhecimento prévio sobre o genoma da espécie avaliada e os primers utilizados são aleatórios, uma série de reações costumam ser realizadas (cada reação um primer) para se avaliar polimorfismo através de RAPD. No entanto, alguns trabalhos têm sugerido que quando a variabilidade genética é elevada em uma população, o uso de poucos primers, ou um menor número de reações seriam suficientes $(8 ; 4)$, o que reduziria custo e tempo operacional.

O objetivo deste trabalho foi otimizar o número de primers utilizados para detectar a variabilidade genética entre acessos da espécie daninha picão-preto suscetíveis e resistentes aos herbicidas inibidores de ALS, através do marcador molecular RAPD.

\section{METODOLOGIA}

Dois experimentos foram analisados com variado número de primers. No primeiro experimento, os acessos de picão-preto eram oriundos de duas propriedades agrícolas no Paraná: Nova Laranjeiras (seis acessos suscetíveis, coletados em uma mesma propriedade, denominados de "N") e Pato Branco (nove acessos resistentes, coletados em áreas diferentes de uma mesma propriedade, denominados de "A" $e$ "P"). No segundo experimento, os acessos suscetíveis (dois) eram originários de Porto Alegre, RS, e os vinte e três acessos resistentes eram originados de Colorado, RS, e Pato Branco, PR. Em ambos os experimentos, as sementes coletadas foram levadas à casa de vegetação da Faculdade de Agronomia - UFRGS, em Porto Alegre, RS, onde foram semeadas em vasos com volume de $500 \mathrm{ml}$, contendo como substrato areia:solo (1:1). Após a emergência, foi realizado o desbaste, permanecendo duas plantas por vaso mantidas em casa de vegetação até atingirem o estádio de seis folhas.

Ao atingirem o estádio de seis folhas, coletaram-se duas folhas das mesmas, as quais foram mantidas em nitrogênio líquido até a extração de DNA que foi feita de acordo com o protocolo de Murray e Thompson (1980) (Tris- $\mathrm{HCl}$ $1 \mathrm{M} \mathrm{pH} 8,0$; EDTA 0,5M; $\mathrm{NaCl} 5 \mathrm{M}$ e $1,1 \%$ de CTAB). Outros reagentes como proteinase K, SDS $20 \%$, fenol, clorofórmio:álcool isoamílico (24:1 v/v) e RNAse foram utilizados para obter alta qualidade de DNA.

Uma prévia seleção de marcadores moleculares foi realizada objetivando-se maior polimorfismo para os acessos de picão-preto (3). No primeiro experimento, vinte primers da Operon Techonologies (Alameda, CA) foram selecionados e, no segundo, quatorze foram selecionados (Tabela 1). As reações de RAPD foram preparadas para um volume final de $25 \mathrm{~mL}$, contendo a solução tampão da enzima Taq DNA polimerase $(20 \mathrm{mM}$ Tris- $\mathrm{HCl}$ e $50 \mathrm{mM} \mathrm{KCl}$ ), 0,2 $\mathrm{mM}$ de cada dNTP, $1,5 \mathrm{mM}$ de $\mathrm{MgCl}_{2}, 0,24 \mathrm{iM}$ de primer; $20 \mathrm{ng}$ de DNA e 1,2 unidades da enzima Taq DNA polimerase. As amplificações foram realizadas em um termociclador PTC-100 MJ Research programado da seguinte forma: $94^{\circ} \mathrm{C}$ por 3 minutos, para desnaturação da fita de DNA, seguido de $1 \mathrm{~min}$ à $94^{\circ} \mathrm{C}, 1 \mathrm{~min}$ à $35^{\circ} \mathrm{C}$ e $2 \mathrm{~min}$ à $72^{\circ} \mathrm{C}$. Um passo final de $10 \mathrm{~min}$ à $72^{\circ} \mathrm{C}$ foi incluído para extensão final dos fragmentos amplificados. Os produtos da amplificação foram separados em gel de agarose a $1,5 \%$, corados em brometo de etídio e visualizados em transluminador UV. Os tamanhos dos fragmentos foram determinados com a utilização do programa Kodak EDAS 290 comparando-se com o padrão de peso molecular de 100 pares de base (DNA Ladder (Invitrogen)). 
TABELA 1 - Seqüência de primers utilizados como marcadores RAPD.

\begin{tabular}{|c|c|c|c|}
\hline Primer & Seqüência (5'-3') & Primer & Seqüência (5'-3') \\
\hline OPP5 & CCCCGGTAAC & OPE13 & CCCGATTCGG \\
\hline OPP6 & GTGGGCTGAC & OPAD1 & CAAAGGGCGG \\
\hline OPP8 & ACATCGCCCA & OPAD8 & GGCAGGCAAG \\
\hline OPP9 & GTGGTCCGCA & ${\text { OPAD } 10^{1}}^{1}$ & AAGAGGCCAG \\
\hline OPP10 & TCCCGCCTAC & OPAD17 & GGCAAACCCT \\
\hline $\mathrm{OPE}^{2}$ & AAGACCCCTC & OPAD18 & ACGAGAGGCA \\
\hline OPE ${ }^{1}$ & CTTCACCCGA & OPAl14 & TGACGGCGGT \\
\hline OPE10 1 & CACCAGGTGA & OPAI19 & AATGCGGGAG \\
\hline OPE $11^{1}$ & GAGTCTCAGG & OPAG1 & CTACGGAGGA \\
\hline OPE $12^{1}$ & TTATCGCCCC & OPAG19 & GTCAGGGCAA \\
\hline OPAG20 1 & TCTCCCTCAG & & \\
\hline
\end{tabular}

${ }_{1}$ Primerutilizado somente no experimento 1.

${ }^{2}$ Primerutilizado somente no experimento 2.

Primer sem nota utilizado em ambos os experimentos.

Para ambos os experimentos, a similaridade genética foi estimada pelo coeficiente de Jaccard, usando 1 para a presença e 0 para a ausência de bandas nos dados de RAPD. Com os dados obtidos pelos géis foi realizada a análise de agrupamento (módulo SAHN do NTSYS), utilizando o método da média das distâncias genéticas (UPGMA Unweighted Pair-Group Method with Arithmetic Means) e construção de dendograma com o auxílio do programa NTSYSpc versão 2.1 (11).

Para a otimização do número de primers, inicialmente, as análises foram realizadas com a redução do número de primers, ao acaso, e anotada a similaridade genética média (SGM) entre os acessos e o número de grupos formados quando se utilizou a SGM como separador. Para ambos os experimentos, foram realizadas regressões lineares e quadráticas entre o número de primers e o coeficiente de Jaccard e entre o número de primers e o número de grupos de acessos formados, conforme a SGM. A significância das regressões foi determinada pelo coeficiente de correlação ( $r$ ) ao nível de $5 \%$ de probabilidade (14). O ponto de mínimo das curvas de regressão quadrática entre o número de primers e o coeficiente de Jaccard foi calculado pela equação $y=b / 2 c$.

\section{RESULTADOS E DISCUSSÃO}

\section{Experimento 1}

A regressão entre o número de primers e o coeficiente de Jaccard indicou resposta quadrática $\mathrm{R}^{2}=0,77(\mathrm{P}<0,05)$. Com o incremento do número de primers (de 1 até 12), o coeficiente de Jaccard reduziuse, sendo que a partir de 12 primers não houveram reduções do coeficiente (Figura 1).

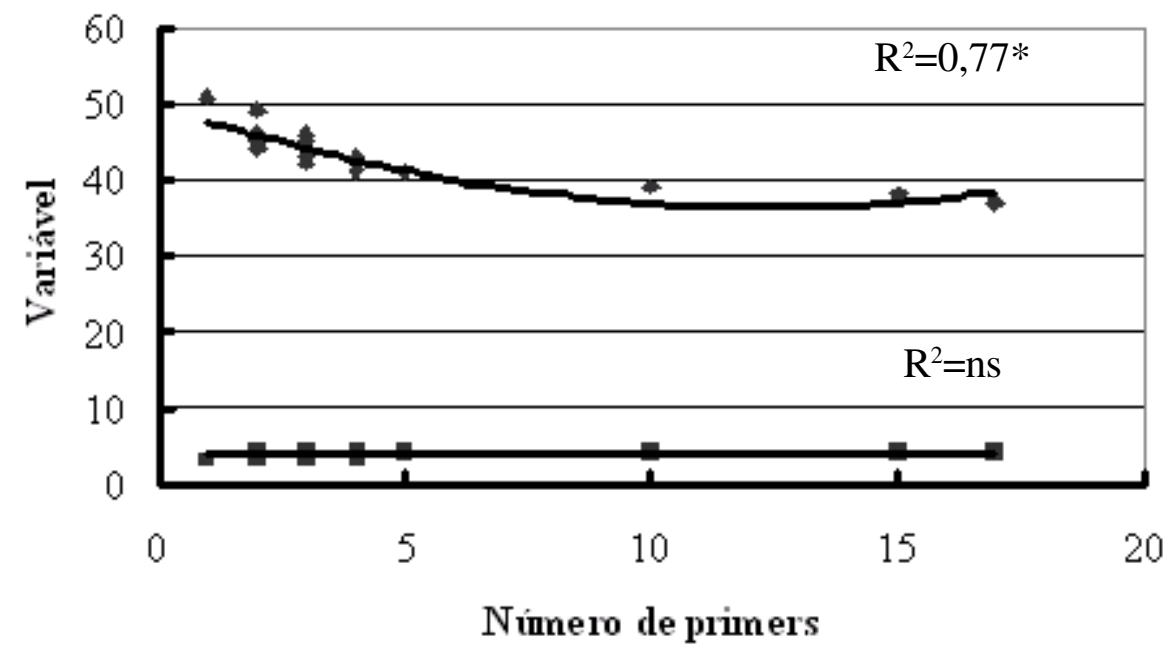

FIGURA 1 - Regressão entre número de primers e coeficiente de Jaccard (?). Regressão entre número de primers e grupos de acessos formados $\left(\begin{array}{l}1 \\ 1\end{array}\right) .\left({ }^{*}=\right.$ coeficiente de correlação) (r) significativo pelo teste $t$, ao nível de $5 \%$ de probabilidade; ns=coeficiente de correlação não significativo). 
VIDAL, R.A. et al. Otimização do número de primers...

Dentre os vinte primers selecionados inicialmente, dezessete apresentaram polimorfismo utilizando marcador RAPD, produzindo amplificações que resultaram em 94 bandas polimórficas, com tamanhos que variaram de 100 a 1600 pb. A análise conjunta dos acessos de picãopreto indicou SGM de 37\%. Quando realizada a análise da similaridade genética entre os acessos de picão-preto com o número de primers otimizado, ou seja, doze, calculado através do ponto de mínimo, foram produzidas 70 bandas polimórficas, com tamanhos que variaram de 100 a 1600 pb. A análise conjunta indicou SGM de $39 \%$ (Figura 2).

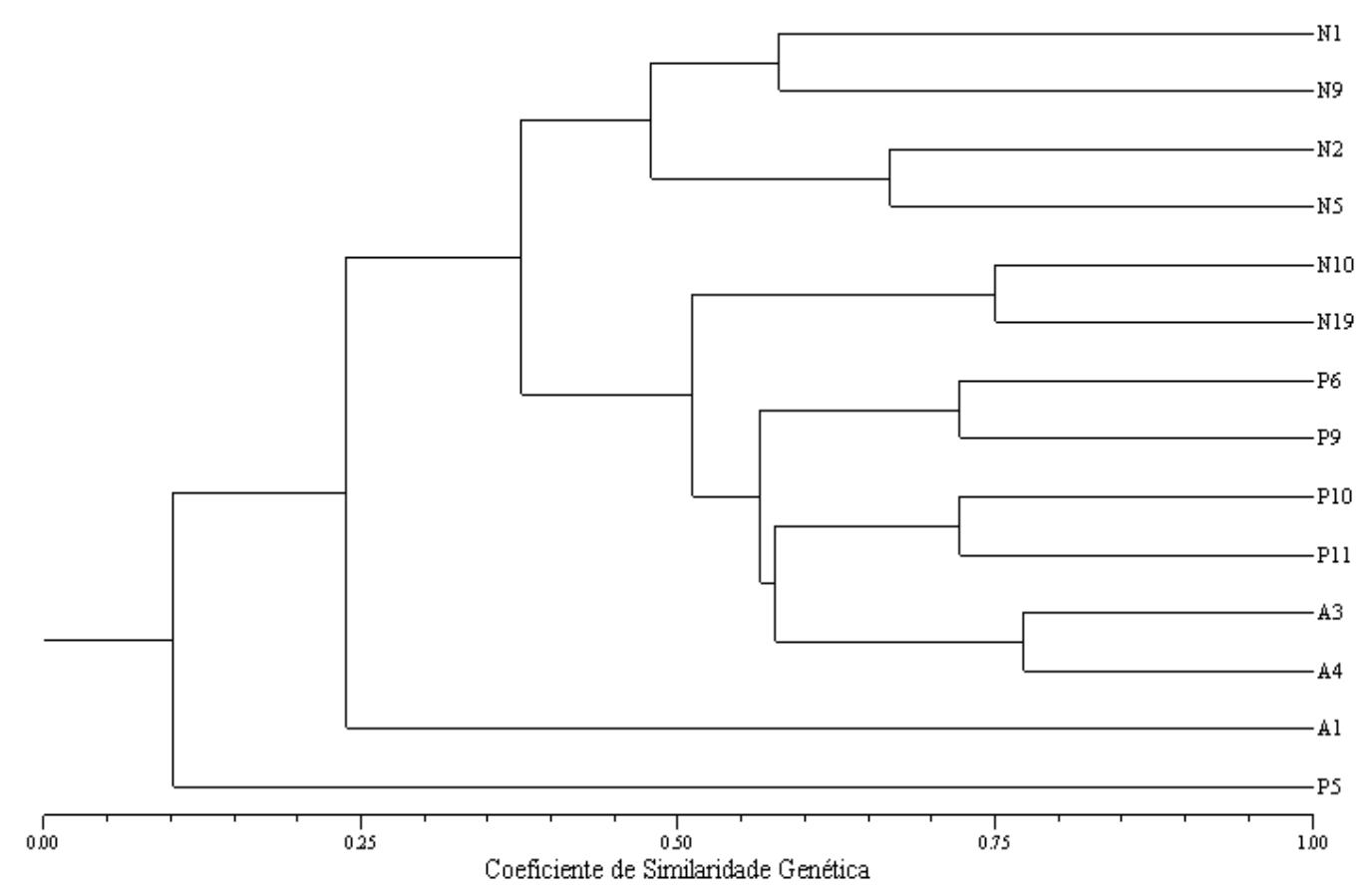

FIGURA 2 - Dendograma de similaridade genética (coeficiente de Jaccard) entre acessos de picão-preto resistentes e suscetíveis aos herbicidas inibidores de ALS, obtido com 12 primers (A linha pontilhada indica similaridade genética média de 39\%).

A regressão entre o número de primers e o número de grupos formados não foi significativa (Figura 1). A análise de agrupamento hierárquico dos acessos com doze primers (otimizado) permitiu a separação em quatro grupos distintos. O primeiro grupo foi composto pelos acessos N1, N2, N5 e N9; o segundo por N10, N19, P6, P9, P10, P11, A3 e A4; o terceiro por A1 e o último por P5 (Figura 2). Quando um número pequeno dentre os primers avaliados promovem boa formação de bandas em cada população, maior número de primers será necessário para fazer estimativa adequada da variabilidade genética.

\section{Experimento 2}

A regressão entre o número de primers e o coeficiente de Jaccard não mostrou significância estatística (Figura 3). Quatorze primers apresentaram polimorfismo utilizando marcador RAPD, produzindo amplificações que resultaram em 63 bandas polimórficas, com tamanhos que variaram de 300 a $1110 \mathrm{pb}$. A análise conjunta dos acessos de picão- preto (com 14 primers) indicou similaridade média de $37 \%$. Como neste caso todos os quatorze primers utilizados promoveram boa formação de bandas, o uso de apenas três primers é suficiente para a análise da SGM entre os acessos, onde foram produzidas 9 bandas polimórficas com tamanhos que variaram de 400 a 1050 pb (Figura 4). A análise conjunta com apenas três primers indicou SGM de 42\% (Figura 4).

A regressão entre o número de primers e 0 número de grupos de acessos formados, semelhante ao Experimento 1, não foi significativa (Figura 3). A análise de agrupamento hierárquico dos acessos com três primers permitiu a separação em sete grupos distintos. O primeiro grupo foi composto pelos acessos 51, 54, 57, 56, 58, 711, 52, 511, 510, 512, $65,66,67,612,710,74$; o segundo por 69 ; o terceiro por 78 e 96; o quarto pelo acesso 27; o quinto por 53, 76 e 73; o sexto por 79 e o último por 55 (Figura 4). Neste experimento observa-se que quando todos os primers promovem boa formação de bandas em cada população, poucos primers são suficientes para fazer estimativa adequada da variabilidade genética. 


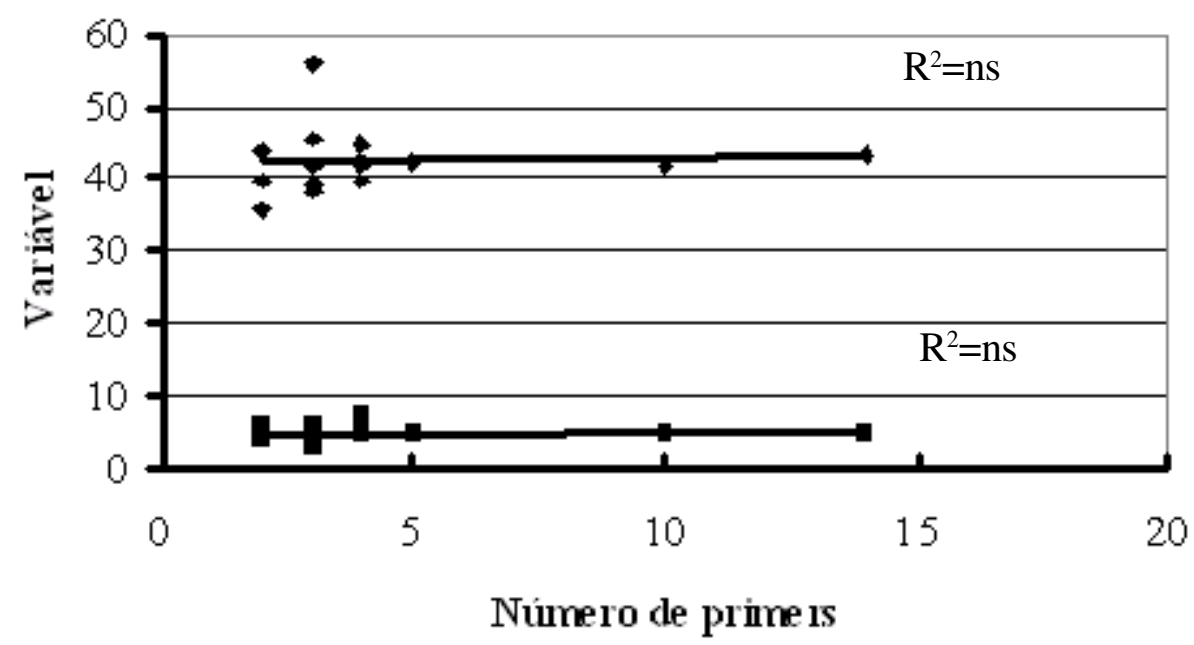

FIGURA 3 - Regressão entre número de primers e coeficiente de Jaccard (?). Regressão entre número de primers e grupos de acessos formados $\left(\begin{array}{l}1 \\ 1\end{array}\right)$. (ns= coeficiente de correlação não significativo pelo teste t, ao nível de $5 \%$ de probabilidade)

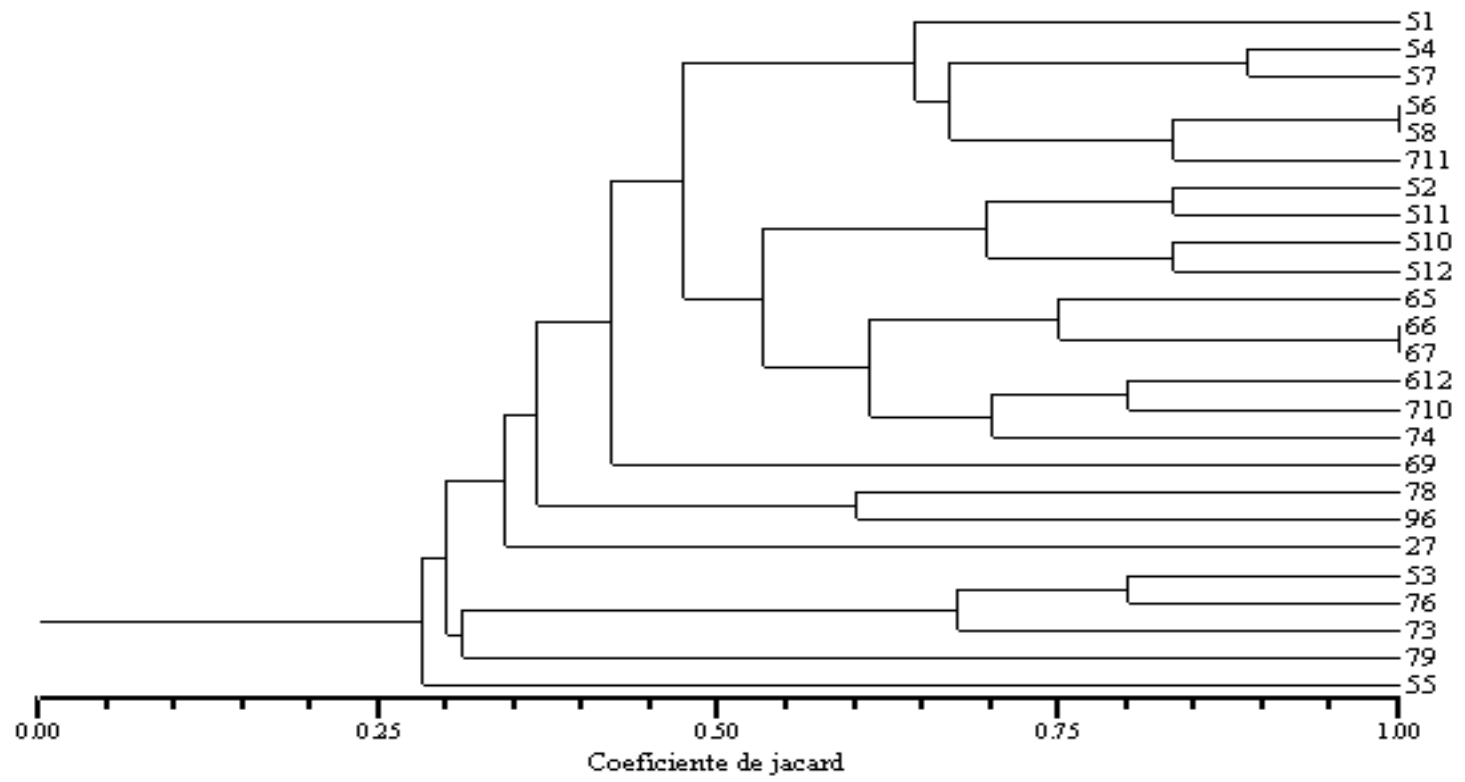

FIGURA 4 - Dendograma de similaridade genética (coeficiente de Jaccard) entre acessos de picão-preto resistentes e suscetíveis aos herbicidas inibidores de ALS, obtido com 3 primers (A linha pontilhada indica similaridade genética média de 42\%). 
Avaliando a diversidade genética através de RAPD entre 38 acessos de Sesamun indicum, observou-se que sete primers foram suficientes para demonstrar variabilidade (1). Também em Setaria itálica apenas quatro primers foram suficientes para identificar variabilidade genética entre 37 acessos (13). $\mathrm{O}$ argumento encontrado na literatura é que quando a variabilidade genética é elevada, o uso de número reduzido de primers é suficiente para acusá-la $(8 ; 4)$.

O presente trabalho, que analisou variabilidade genética entre acessos da espécie daninha picãopreto, confirma o que se encontra na literatura. Em geral, espera-se que em espécies daninhas haja elevada variabilidade uma vez que não sofreram melhoramento genético. Todavia, outros fatores como deriva genética ou efeito fundador também podem contribuir efetivamente para a diminuição da variabilidade genética dentro de populações daninhas, justificando que não apenas o fato de não passarem por melhoramento garanta variabilidade elevada. No caso específico de picão-preto, por ser uma espécie autógama, a recombinação atua na manutenção da variabilidade na população. Caso os primers utilizados produzam boa amplificação de bandas, então poucos primers são suficientes para fazer a estimativa adequada da variabilidade genética.

Apesar de apresentar algumas limitações como problemas relacionados com a padronização de condições de amplificação, dentre outros, a técnica de RAPD não requer conhecimento prévio sobre a espécie vegetal a ser analisada, o que representa um benefício desta técnica na análise inicial de populações de plantas daninhas e de plantas nativas $(2 ; 7)$.

Para ser possível a otimização no número de primers utilizados, são necessários testes preliminares para se ter conhecimento dos primers que promovem boa amplificação do DNA da espécie em estudo. Para isso, há necessidade de se testar vários primers em algumas populações dentre as de interesse e realizar o estudo de otimização proposto neste trabalho. $\mathrm{Na}$ seqüência, analisam-se todas as populações de interesse, utilizando-se apenas a quantidade de primers obtida na otimização. A otimização proposta permitirá economizar custos e tempo para estimar a variabilidade genética de uma espécie.

A otimização de primers encontrada na literatura normalmente refere-se à seleção de primers que produzam maior número de bandas $(10 ; 15 ; 5)$. $\mathrm{Na}$ espécie Anacardium occidentale L., foi observado que os primers de RAPD OPA-02 e OPN-03 foram responsáveis pela máxima produção de fragmentos de DNA quando a cultivar avaliada foi H-320 (12). No entanto, a inovação do presente trabalho está em mostrar que é possível otimizar o número de primers utilizados na caracterização da variabilidade genética das populações em estudo.

\section{CONCLUSÕES}

É possível otimizar o número de primers utilizados por marcadores moleculares RAPD. Quando poucos primers promovem boa formação de bandas em cada população, maior número de primers serão necessários para adequada estimativa da variabilidade genética. Todavia, quando muitos primers promovem boa formação de bandas em cada população, poucos são suficientes para estimativa adequada da variabilidade genética.

\section{AGRADECIMENTOS}

A CAPES, CNPq e FAPERGS pelo apoio à pesquisa.

\section{REFERÊNCIAS}

1. ERCAN, A. G.; TASKIN, M.; TURGUT, K. Analysis of genetic diversity in turkish sesame (Sesamum indicum L.) populations using RAPD markers. Genetics Resources and Crop Evolution, Dordrecht, v.51, n.6, p.599-607, 2004.

2. FERREIRA, M. E.; GRATTAPAGLIA, D. Introdução ao uso de marcadores moleculares em análise genética. 3.ed. Brasília: Embrapa-Cenargen, 1998. 220p.

3. HERNANDES, G. C. Resistência de Bidens spp. aos herbicidas inibidores de acetolactato sintase: análise de populações com marcadores moleculares e estratégias para seu manejo. 2004. 109p. Dissertação (Mestrado) - Programa de PósGraduação em Fitotecnia, Faculdade de Agronomia, Universidade Federal do Rio Grande do Sul, Porto Alegre, 2004.

4. LI, M.; MIDMORE, D. J. Estimating the genetic relationships of Chinese water chestnut (Eleocharis dulcis (Burn. f.) Hensch) cultivated in Australia, using random amplified polymorphic DNAs (RAPDs). Journal of Horticultural Science and Biotechnology, Rockhampton, v.74, n.2, p.224-231, 1999.

5. LIM, S. H.; PHUA, D. C. Y; TAN, H. T. W. Primer design and optimization for RAPD analysis of Nepenthes. Biologia Plantarum, V.43, n.1, p.153-155, 2000.

6. LIU, C. J. Geographical distribution of genetic variation in Stylosanthes scabra revealed by RAPD analysis. Euphytica, Dordrecht, v.98, n.1-2, p.21-27, 1997.

7. MILACH, S. C. K. Marcadores moleculares em plantas. Porto Alegre: S.C.K. Milach, 1998. 141p.

8. MILLAN, T.; OSUNA, F.; COBOS, S.;TORRES, A. M.; CUBERO, A. M. Using RAPDs to study phylogenetic relationships in rosa. Theorical and Applied Genetics, Cordoba, v.92, n.2, p.273-277, 1996.

9. MURRAY, M. G.; THOMPSON, W. F. Rapid isolation of high molecular weight plant DNA. Nucleic Acids Research, Oxford, v.8, n.9, p.4321-4325, 1980. 
10. OIU, J.; VANSANTEN, E.; TUZUN, S. Optimization of DNA amplification fingerprinting techniques to study genetic relationships of white lupin germplasm. Plant Breeding, Shiltigheim, v.114, n.6, p.525-529, 1995.

11. ROHLF, F. J. Numerical taxonomy and multivariate analysis system. Port Jefferson: Applied Biostatistics, 2000. 38p.

12. SAMAL, S.; ROUT, G. R.; NAYAK, S.; NANDA, R. M.; LENKA, P. C.; DAS, P. Primers screening and optimization for RAPD analysis of cashew. Biologia Plantarum, v.46, n.2, p.301-304, 2003.

13. SCHOLTZ, D.; RETHER, B. Genetic variability in foxtail millet, Setaria italica (L.) P. Beauv. Identification and classification of lines with RAPD markers. Plant Breeding, Shiltigheim, v.118, n.2, p.190-192, 1999.

14. STEEL, R. G. D.; TORRIE, J. H. Principles and procedures of statistics: a biometrical approach. New York: McGraw, 1976. $672 p$.

15. TESSIER, C.; DAVID, J.; THIS, P.; BOURSIQUOT, J. M.; CHARRIER, A. Optimization of the choice of molecular markers for varietal identification in Vitis vinifera L.Theoretical and Applied Genetics, Cordoba, v.98, n.1, p.171-177, 1999.

16. WILLIAMS, J. G. K. et al. DNA polymorphisms amplified by arbitrary primers are useful as genetic markers. Nucleic Acids Research, v.18, n.22, p.6531-6535, 1990.

17. XU, C.; ZHANG, W.; FU, C.; LU, B. Genetic diversity of alligator weed in China by RAPD analysis. Biodiversity and Conservation, Dordrecht, v.12, n.4, p.637-645, 2003.

Recebido em 26/08/2005 Aceito em 16/11/2005 